\title{
Prehospital control of life-threatening truncal and junctional haemorrhage is the ultimate challenge in optimizing trauma care; a review of treatment options and their applicability in the civilian trauma setting
}

\author{
S. E. van Oostendorp ${ }^{1 *}$ D, E. C. T. H. $\operatorname{Tan}^{2,3}$ and L. M. G. Geeraedts $\mathrm{Jr}^{1}$
}

\begin{abstract}
Introduction: Exsanguination following trauma is potentially preventable. Extremity tourniquets have been successfully implemented in military and civilian prehospital care. Prehospital control of bleeding from the torso and junctional area's remains challenging but offers a great potential to improve survival rates. This review aims to provide an overview of potential treatment options in both clinical as preclinical state of research on truncal and junctional bleeding. Since many options have been developed for application in the military primarily, translation to the civilian situation is discussed.

Methods: Medline (via Pubmed) and Embase were searched to identify known and potential prehospital treatment options. Search terms werel: haemorrhage/hemorrhage, exsanguination, junctional, truncal, intra-abdominal, intrathoracic, intervention, haemostasis/hemostasis, prehospital, en route, junctional tourniquet, REBOA, resuscitative thoracotomy, emergency thoracotomy, pelvic binder, pelvic sheet, circumferential. Treatment options were listed per anatomical site: axilla, groin, thorax, abdomen and pelvis Also, the available evidence was graded in (pre) clinical stadia of research.

Results: Identified treatment options were wound clamps, injectable haemostatic sponges, pelvic circumferential stabilizers, resuscitative thoracotomy, resuscitative endovascular balloon occlusion of the aorta (REBOA), intra-abdominal gas insufflation, intra-abdominal self-expanding foam, junctional and truncal tourniquets. A total of 70 papers on these aforementioned options was retrieved. No clinical reports on injectable haemostatic sponges, intra-abdominal insufflation or self-expanding foam injections and one type of junctional tourniquets were available.

Conclusion: Options to stop truncal and junctional traumatic haemorrhage in the prehospital arena are evolving and may offer a potentially great survival advantage. Because of differences in injury pattern, time to definitive care, different prehospital scenario's and level of proficiency of care providers; successful translation of various military applications to the civilian situation has to be awaited. Overall, the level of evidence on the retrieved adjuncts is extremely low.
\end{abstract}

Keywords: Trauma, Haemorrhage, Exsanguination, Intervention, Prehospital, Junctional, Truncal, Bleeding

\footnotetext{
* Correspondence: s.vanoostendorp@vumc.nl

${ }^{1}$ Department of Trauma Surgery, VU University Medical Center, P.O. Box 7057

1007 MB Amsterdam, The Netherlands

Full list of author information is available at the end of the article
} 


\section{Background}

Haemorrhage due to trauma is the leading preventable cause of death in the military setting, accounting up tot to $90 \%$ of potentially preventable deaths $[1,2]$. In the civilian setting, it is the second most leading cause of death in trauma patients, studies report: 26-40\% [3, 4]. Only head injury is considered more lethal [3, 4]. Fiftysix per cent up to $87 \%$ for respectively civilian and combat-related mortality caused by traumatic haemorrhage occurs before reaching definitive care $[2,5,6]$. So, early (e.g., prehospital) haemorrhage control allowing for bridging to definitive surgical care, may yield a large survival advantage.

Life-threatening haemorrhage is a time dependent 'disease' in which the duration of ongoing bleeding may lead to either death or, in case of initial survival and subsequent massive transfusion, to possible sepsis and/or multi-organ failure [7-9]. Haemorrhage control, among shock resuscitation and prevention of trauma-induced coagulopathy, are the mainstays of treatment of imminent exsanguination in the prehospital arena as well as in the definitive care facility [9].

Treatment options for ongoing haemorrhage in the prehospital arena are limited. In case of blunt trauma and closed extremity injuries, (traction) splinting of limbs and/or stabilizing the pelvis reduces blood loss until definitive care [10]. In open fractures caused by blunt trauma and in extremity injuries resulting from penetrating trauma or blast; external blood loss is limited by the use of extremity tourniquets, with excellent results in the military $[11,12]$ and civilian [13-16] setting. Extreme nasopharyngeal and/or oropharyngeal bleeding can be countered by gauze packing and/or improvised Bellocq-tamponade with Foley-catheters $[17,18]$. Hemostatic suturing, direct digital pressure and the use of pressure bandages will prevent ongoing blood loss from external wounds such as scalp lacerations [19-21]. Moreover, for the last 15 years [22] there has been an ongoing development of haemostatic gauze dressings that can be used as an adjunct to compression in stopping major blood loss from external wounds. Their applicability and efficacy have been published in recent review articles [22-24]. As with the tourniquet, the use of haemostatic gauze dressings has found its way from the battlefield to application in the civilian prehospital setting $[25,26]$, although widespread implication of both treatment options has not been achieved [27, 28]. However, through the Hartford Consensus and in the context of prehospital care in mass shootings and/or bomb explosions in the civilian situation, application of tourniquets and haemostatic gauze dressings by non-(para) medical responders and lay persons is promoted to stop bleeding early [29, 30]. Half day training courses for these immediate responders have been set up [31].
In the prehospital arena, stopping major bleeding from anatomical sites where the application of an extremity tourniquet or pressure bandage is not feasible, remains the greatest challenge. Bleeding from the so-called junctional area's: axillae, groins and neck are compressible. Direct digital pressure combined with haemostatic gauze dressings are temporizing measures but may not be feasible under hectic, tactical prehospital circumstances and/or prolonged extraction and transport procedures.

For non-compressible bleeding from the trunc: options for (temporary) control of intrathoracic, intra-abdominal, and intrapelvic haemorrhage are extremely limited in the prehospital arena and haemorrhage control in these cases may demand expert surgical approach [32].

The aim of this review is to provide an overview of modern (experimental) treatment options for control of junctional and truncal haemorrhage in the prehospital arena. Also, since most developments are ensuing from necessities in the battlefield situations, the applicability of the treatment options are discussed in the light of the civilian setting and especially in the context of differences in patient demographics, trauma mechanism and prehospital situations.

\section{Methods}

Exploration of existing reports in the literature was done by a search of Medline (via Pubmed) and Embase at December 22th 2015 without restriction to publication date. Papers eligible for inclusion had to be written in English. No restriction was applied to the stage of research, i.e., articles on both clinical and preclinical research were eligible. The search was performed of the following terms in various combinations: haemorrhage/ hemorrhage, exsanguination, junctional, truncal, intraabdominal, intrathoracic, intervention, haemostasis/ hemostasis, prehospital, en route, junctional tourniquet, REBOA, resuscitative thoracotomy, emergency thoracotomy, pelvic binder, pelvic sheet, circumferential. Initially, all study reports of interventions regardless of design (i.e., trials, case-series, case-reports and reviews) were included. All abstracts were assessed for the potential for prehospital applicability of the intervention in case of haemorrhage by experienced prehospital trauma care providers (ET and LG). References of the reports were scanned to retrieve additional studies.

The focus of this review was on reports of prehospital or experimental (i.e., cadaveric or animal) prehospital procedures. However, if such reports on certain body areas were scarce, we included recent studies reporting in-hospital emergency department procedures that potentially could be applied prehospitally. The interventions of the selected studies were allocated to 5 anatomical areas of interest: junctional: 1) axilla, 2) groin and truncal 3) chest, 4) abdomen and 5) pelvis The results are 
described per anatomical area and presented in a table ordered by (pre) clinical stadium of research. Finally, an appraisal of potential applicability in the prehospital arena is provided by listing pro's and con's as discussed in meetings by the authors of this review.

\section{Results}

\section{Junctional haemorrhage}

Junctional haemorrhage is defined as bleeding from a junction of the torso to the extremities, i.e., the base of the neck, shoulder, axilla, perineum, buttocks, gluteal area and the groin [33]. A study of casualties in the U.S. combat forces from 2001 to 2011 , noted that $17.5 \%$ of potentially preventable prehospital deaths resulted from junctional haemorrhage [2]. No reports on the incidence of junctional haemorrhage in the civilian situation were found.

\section{Junctional haemorrhage - axilla- direct pressure}

The axilla is a vulnerable spot, poorly protected by armoured vests in the military setting. An extremity tourniquet is considered as treatment of first resort in haemorrhage of the upper extremity. If bleeding persists despite an adequately applied tourniquet or the site of bleeding is too proximal to apply a tourniquet, military guidelines advocate to start with a haemostatic gauze in combination with direct pressure [33]. The prehospital use and efficacy of haemostatic gauzes has been reviewed extensively [22-24] and will not be discussed. After animal-model testing [34], the FDA approved XSTAT-30 ${ }^{\text {Tx }}$ (RevMedx, Wilsonville, Ore), a syringe-like device containing dozens of small compressed chitosan covered cellulose sponges that can be injected in junctional bleedings and secured with regular bandages. Intrathoracic, -pelvic or -abdominal use are contra-indicated [35]. No clinical use was yet reported at the time of this review.

\section{Junctional haemorrhage - axilla- junctional tourniquets}

A downside of applying direct pressure is that a care provider is no longer available to perform other interventions. In the military, due to tactical circumstances and longer retrieval times, this has led to a request for mechanical devices to free the hands of the medical care provider.

Four junctional tourniquets which can be used in case of junctional haemorrhage are the Combat Ready Clamp $(\mathrm{CRoC})^{\mathrm{m}}$, Junctional Emergency Tool (JETT) $)^{\mathrm{m}}$, SAM Junctional Tourniquet (SAM-JT) ${ }^{\mathrm{mm}}$ and Abdominal Aortic Junctional Tourniquet (AAJT) ${ }^{\mathrm{mm}}$ [33]. Simultaneous use of haemostatic dressings and (junctional) tourniquets may work synergistic in controlling haemorrhage $[33,36]$.

The $\mathrm{CRoC}^{\mathrm{mx}}$ has been FDA-cleared for axillary haemorrhage and has shown to be effective in a cadaver model [37]. It is a device which consists of a stamp compressing the targeted area underneath. See Fig. 1. It has been

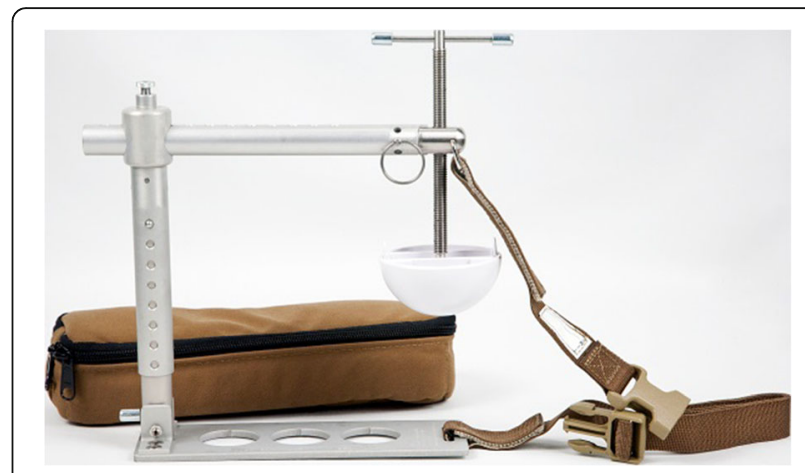

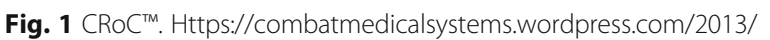
05/06/combat-ready-clamp-croctm-makes-tactical-medicine-history/

reflected that the $\mathrm{CRoC}^{\mathrm{m}}$ is heavy and assembling takes too long (1-2 min) [38]. However, in civilian prehospital care, a ready-to-use pre-assembled unit can be stored in an ambulance or helicopter [33].

At the time of this review no studies on the use of $\mathrm{JETT}^{\mathrm{mi}}$ or SAM-JT $\mathrm{T}^{\mathrm{m}}$ junctional tourniquet for axillary bleeding were available.

The AAJT ${ }^{\mathrm{max}}$ has been successfully used in the civilian setting in case of a gunshot wound to the axilla [39]. The wedge-formed bladder was positioned in the axilla and the device strapped around the torso. No further bleeding from the axilla was seen after inflating the bladder up to $250 \mathrm{mmHg}$ pressure. Radiographic imaging showed some compression of the left thorax, but ventilator inspiratory pressures were normal [39]. An observational trial in human volunteers showed successful eliminated blood flow in the brachial artery in axillary application of the AAJT ${ }^{\mathrm{Tm}}$ using a mean pressure of $168 \mathrm{mmHg}$. Doppler measurement showed complete elimination of flow and spontaneous recovery of flow when the AAJT ${ }^{\mathrm{Tx}}$ was deflated [40].

\section{Junctional haemorrhage - axilla- wound clamp}

When a junctional tourniquet is not available, or will take too much time to apply and/or when maintaining direct pressure is not an option, the use of the iTClamp (Innovative Trauma Care Inc., Edmonton, Alberta, Canada) may be considered. The iTClamp ${ }^{\mathrm{Tm}}$ is a mechanical clamp which looks like a hair clamp with several small needles that seals a wound by approximating the wound edges of the overlying skin firmly, creating a compartment in which the bleeding potentially tamponades. See Fig. 2 . Several reports of field use exist $[41,42]$. See Table 1. With the iTClamp ${ }^{\mathrm{mm}}$ haemorrhage control was gained in 9 out of 10 applications for venous or arterial and venous combined origin in scalp $(n=7)$, neck, chest wall, and lacerations from open femoral fractures. The clamp failed to control haemorrhage from a combined carotid and vertebral arterial laceration in the neck. By packing the wound with haemostatic gauze, reapplication of the 


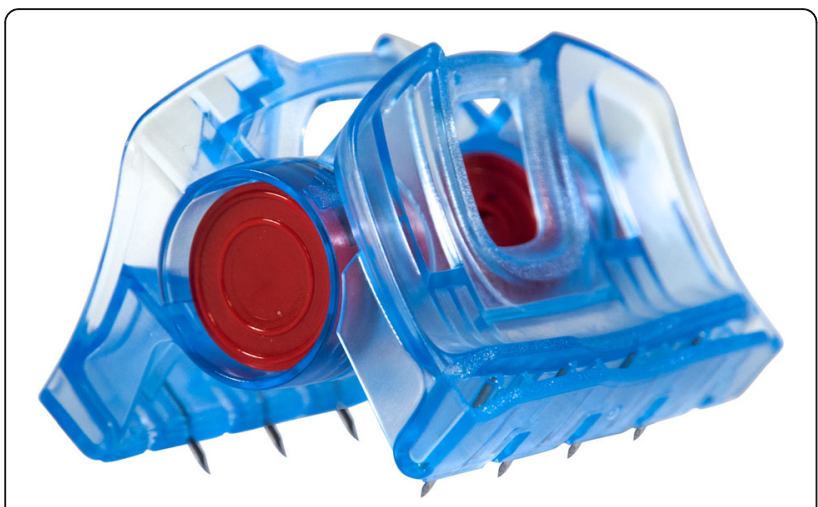

Fig. 2 iTClamp ${ }^{T M}$. Image provided by manufacturer
iTClamp $^{\text {tw }}$ and direct pressure haemorrhage control was achieved [42].

\section{Junctional haemorrhage - groin}

Like in axillary haemorrhage, extremity tourniquets are not applicable in groin/inguinal or proximal lower extremity bleeding. Military guidelines advocate application of haemostatic gauze and direct manual or digital pressure in expectation of a junctional tourniquet [33].

\section{Junctional haemorrhage - groin - junctional tourniquets}

The JETT ${ }^{\mathrm{Tu}}$ and SAM-JT ${ }^{\mathrm{Tm}}$ can be used in bi- or unilateral inguinal or lower extremity haemorrhage. The $\mathrm{CRoC}^{\mathrm{tm}}$ is a unilateral device. Previously, the AAJT ${ }^{\mathrm{m} x}$ had only FDA

Table 1 Overview of retrieved studies covering the identified prehospital treatment options, ordered by anatomical site, device and stage of (pre-clinical) research

\begin{tabular}{|c|c|c|c|c|c|c|c|c|}
\hline \multirow[t]{2}{*}{ Site } & \multirow[t]{2}{*}{ Device } & \multicolumn{3}{|c|}{ Clinical } & \multicolumn{3}{|c|}{ Preclinical } & \multirow{2}{*}{$\begin{array}{l}\text { Physician } \\
\text { required? }\end{array}$} \\
\hline & & $\begin{array}{l}\text { Prehospital } \\
\text { civilian }\end{array}$ & $\begin{array}{l}\text { Prehospital } \\
\text { military }\end{array}$ & Inhospital & Volunteer & Cadaver/manikin & Animal & \\
\hline \multirow[t]{6}{*}{ Axilla } & CRoC & - & - & - & - & {$[37]$} & - & No \\
\hline & JETT & - & - & - & - & - & - & No \\
\hline & SAM-JT & - & - & - & - & - & - & No \\
\hline & AAJT & [39] & - & - & {$[40]$} & - & - & No \\
\hline & iTClamp & - & - & - & - & - & - & No \\
\hline & Xstat-30 & - & - & - & - & - & [34] & No \\
\hline \multirow[t]{8}{*}{ Groin } & CRoC & - & {$[45]$} & - & [43] & {$[47,128,129]$} & {$[38,130]$} & No \\
\hline & JETT & - & - & - & {$[43]$} & {$[47,129]$} & - & No \\
\hline & SAM-JT & - & {$[48]$} & - & [43] & [129] & - & No \\
\hline & AAJT-Groin & - & {$[50]$} & - & {$[40]$} & - & - & No \\
\hline & AAJT-Truncal & - & [49] & - & {$[43,44,46]$} & [129] & & No \\
\hline & iTClamp & [53] & [41] & - & - & {$[52]$} & {$[51,131]$} & No \\
\hline & Xstat-30 & - & - & - & - & - & [34] & No \\
\hline & REBOA & - & - & {$[54,98]$} & - & - & {$[64,132]$} & Yes \\
\hline \multirow[t]{4}{*}{ Abdominal } & REBOA & - & - & {$[54,61,62,97,98]$} & - & - & {$[57,58,63,96,113]$} & Yes \\
\hline & $\begin{array}{l}\text { Resuscitative } \\
\text { thoracotomy }\end{array}$ & {$[66,70,71]$} & - & {$[62,76]$} & - & - & - & Yes \\
\hline & Insufflation & - & - & - & - & - & [84-88] & No \\
\hline & ResQFoam & - & - & - & - & [94] & {$[82,83,89-92]$} & No \\
\hline \multirow[t]{2}{*}{ Thorax } & $\begin{array}{l}\text { Resuscitative } \\
\text { thoracotomy }\end{array}$ & {$[66,69-72,74]$} & - & [76] & - & - & - & Yes \\
\hline & REBOA & - & - & - & - & - & - & Yes \\
\hline \multirow[t]{7}{*}{ Pelvis } & Sheet & - & - & {$[110,133-135]$} & - & {$[136,137]$} & - & No \\
\hline & AAJT-Truncal & - & - & - & {$[46]$} & - & - & No \\
\hline & TPOD & - & - & {$[107,108]$} & [138] & {$[111,136,137]$} & - & No \\
\hline & SAM-Sling & - & - & [109] & [138] & {$[111,139,140]$} & - & No \\
\hline & Pelvic Binder & - & - & [110] & {$[138,141]$} & [11 11$]$ & - & No \\
\hline & Resuscitative thoracotomy & {$[66,70-72,74]$} & - & {$[61,62]$} & - & - & [95] & Yes \\
\hline & REBOA & [116] & - & {$[54,60-62,98]$} & - & - & {$[95,113,115]$} & Yes \\
\hline
\end{tabular}


clearance for umbilical application, which occludes the abdominal aorta and can be used for bilateral inguinal or pelvic haemorrhage $[43,44]$. See Fig. 3 . The clearance has been expanded to junctional use: placement over the groin provides unilateral occlusion of arterial flow at the common femoral artery [40].

The $\mathrm{CRoC}^{\mathrm{m} \mathrm{M}}$ has been reported to be effective in clinical, cadaver, manikin and animal studies in groin bleeds. See Table 1. Tovmassian et al. reported a case using the $\mathrm{CRoC}^{\mathrm{m} \mathrm{m}}$ successfully in a proximal lower extremity traumatic amputation on the battlefield. Haemorrhage was controlled rapidly after assembling and applying of the $\mathrm{CRoC}^{\mathrm{rm}}$ which took $90 \mathrm{~s}$ [45]. Potential dislodgement during combat situations or transport has been mentioned as a concern of $\mathrm{CRoC}^{\mathrm{TM}}$ use [46].

The JETT $^{\mathrm{TM}}$ is designed as a belt including two pressure pads with threaded T-handles. See Fig. 4. It stabilises the pelvic ring and provides the option of bilateral haemorrhage control by compressing the common femoral artery, thereby occluding arterial blood flow to the lower extremities. Application time to occlude bilateral flow in a cadaveric study was about $10 \mathrm{~s}$ with JETT ${ }^{\mathrm{rm}}$. In contrast, bilateral $\mathrm{CRoC}^{\mathrm{Tm}}$ application (two devices) took $68 \mathrm{~s}$ [47].

The design of the SAM-JT ${ }^{\mathrm{TM}}$ is similar to the $\mathrm{JETT}^{\mathrm{TN}}$ : designed like a belt, but instead of threated T-handles, the SAM-JT ${ }^{\mathrm{TM}}$ is equipped with two pneumatically inflatable bladders to compress the common femoral artery uni- or bilateral. See Fig. 5. Klotz et al. reported the use of the SAM-JT ${ }^{\mathrm{rm}}$ in inguinal bleeding of an Afghan soldier. In combination with haemostatic gauze, haemorrhage was adequately stopped [48].

The Abdominal Aortic and Junctional Tourniquet ${ }^{\mathrm{TM}}$, formerly known as Abdominal Aortic Tourniquet ${ }^{\mathrm{TM}}$, can be used in several ways. We previously mentioned the use of the $\mathrm{AAJT}^{\mathrm{\tau}}$ in axillary bleeding. The $\mathrm{AAJT}^{\mathrm{\tau} \mathrm{m}}$ can also be placed over the groin and has a truncal application compressing the distal aorta in the infra-renal zone at the umbilical region. In this way, bilaterally arterial blood

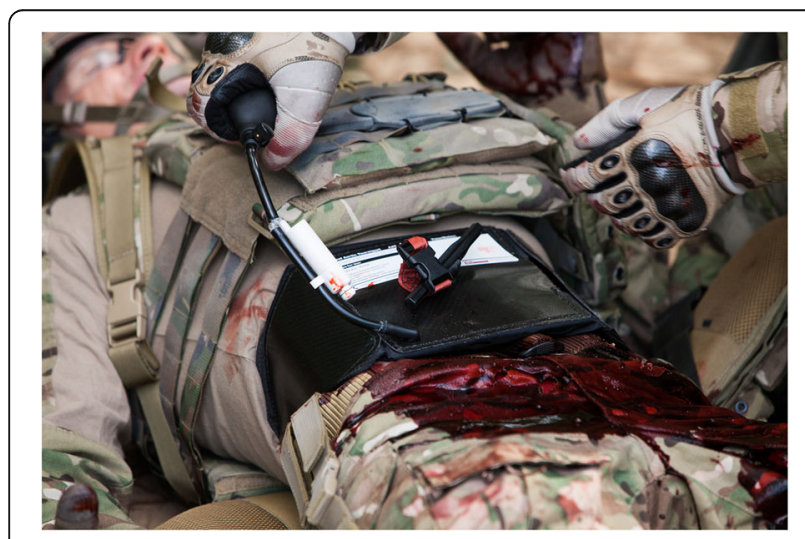

Fig. $3 A A J T^{T M}$. Image provided by manufacturer

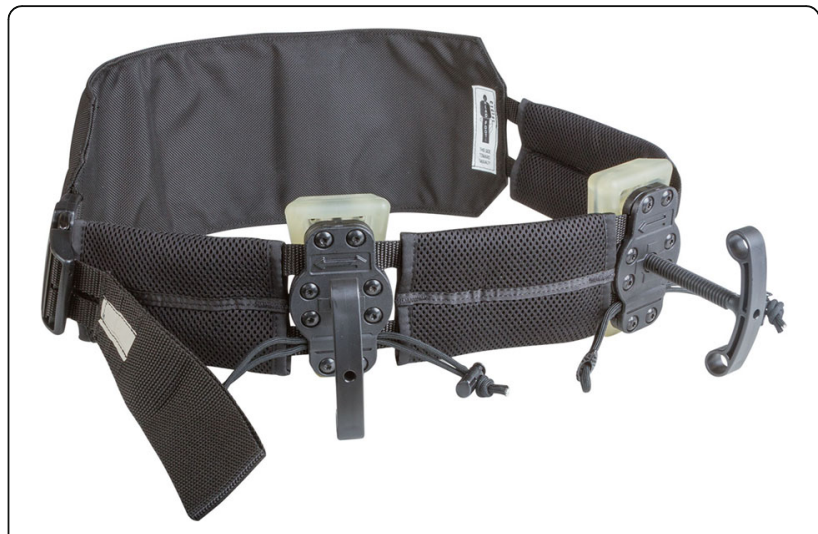

Fig. $4 \mathrm{JETT}^{\mathrm{T}}$. Image provided by manufacturer

flow to the lower extremities and to the pelvic region is blocked. Successful usage of junctional as well as truncal application has been reported in the military setting $[49,50]$. Truncal application in animals was found to have minimal side effects when used for $30 \mathrm{~min}$. Pregnancy, abdominal aneurysm and penetrating abdominal trauma are considered to be contraindications for truncal use of the AAJT ${ }^{\mathrm{rm}}$ [44].

Kragh et al. compared the four junctional tourniquets in a simulated out-of-hospital situation by army medics. Unfortunately, at the time of the study, the AAJT ${ }^{\mathrm{TM}}$ was only FDA-cleared for truncal application. U.S. armed forces medics preferred the CRoC $\mathrm{C}^{\mathrm{TM}}$ and SAM-JT ${ }^{\mathrm{TM}}$ over the $\mathrm{JETT}^{\mathrm{TM}}$ and (truncal) AAJT ${ }^{\mathrm{TM}}$ if they could bring one device on a mission, after testing the various designs at each other [43]. Kotwal et al. reported feedback from battlefield use. The AAJT ${ }^{\mathrm{TM}}$ was reported "to be easily broken" and the $\mathrm{CRoC}^{\mathrm{ma}}$ as "bulky, heavy and takes too

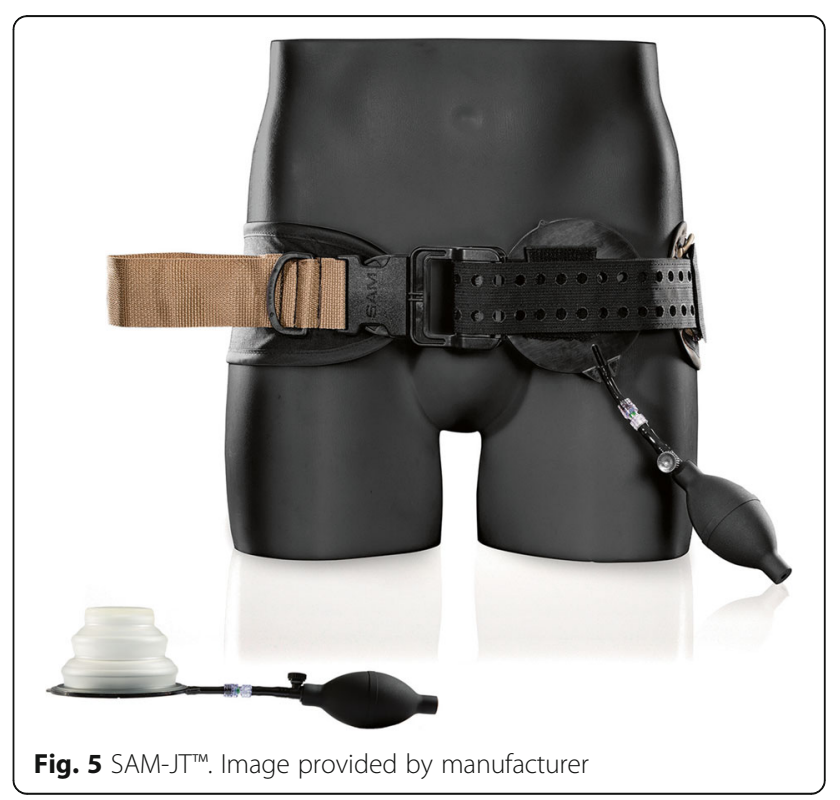


much time to apply" but evacuation units carry it preassembled in their (air) vehicles [33].

\section{Junctional haemorrhage - groin - wound clamp}

The iTClamp ${ }^{\text {tw }}$ has been proven to be feasible in swine and perfused cadaver models with lethal femoral artery bleeding $[51,52]$. Two case reports in which the iTClamp ${ }^{\mathrm{mw}}$ stopped inguinal or proximal lower extremity bleeding were published in respectively non-combatant military and civilian cases [41,53] See Table 1.

\section{Junctional haemorrhage - groin - aortic balloon occlusion}

Resuscitative endovascular balloon occlusion of the aorta (REBOA) is an intervention that shows promising results in patients with non-compressible haemorrhage of the torso [54]. Endovascular balloon occlusion of the aorta was first described by Hughes to control an intraabdominal bleeding in the operating room during the Korean war [55]. REBOA was abandoned after the high complication rate of $35 \%$ reported by Gupta et al. in 1989. Several cases of paraplegia, thrombosis and the catheter exiting the aorta were found [56]. A recent publication of a 60 min lasting thoracic deployment of REBOA in 16 swine resulted in 4 cases of spinal ischaemia, of which 2 were lethal [57]. REBOA requires femoral arterial access for the introduction of a catheter which, after inflation, occludes the aorta. This leads to a decreased blood flow at the site of injury (distally from the balloon), and secondly to an increased central aortic pressure (CAP) [58]. Stannard et al. published an article describing a step-by-step procedure of REBOA use [59]. Zones for balloon deployment are the thoracic Zone I (left subclavian artery to coeliac artery) and zone III (infra renal aorta), for intra-abdominal or pelvic/inguinal haemorrhage respectively [59]. Several series of emergency department (ED) use of REBOA have been reported, but predominantly in cases of pelvic haemorrhage [54, 60-62]. The first prehospital REBOA intervention was performed by the London Helicopter Emergency Medical Service (HEMS) and will be discussed in the paragraph on pelvic haemorrhage. To facilitate prehospital REBOA, smaller (Fr7) balloon catheters and contrast-enhanced ultrasonic control for adequate positioning have been developed and tested in preclinical animal studies $[63,64]$. Usage of REBOA to control junctional haemorrhage from the groin and lower extremities has not been described but may deem feasible.

\section{Intra-thoracic haemorrhage}

\section{Intra-thoracic haemorrhage - resuscitative thoracotomy}

Resuscitative thoracotomy (RT) is a radical intervention which can be performed by any physician that can handle a scalpel $[65,66]$. At the appropriate timing, RT enables relief of cardiac tamponade, aortic cross-clamping, pulmonary hilar clamping or twisting and internal cardiac compression [65-69]. Recent studies suggest that prehospital RT in case of penetrating trauma, more specifically stab wounds, could benefit that subcategory of patients [70]. Chance of survival for patients with gunshot wounds $[65,71]$ or blunt trauma are poor $[65,70,72]$. The London Helicopter Emergency Medical Service reported prehospital (or field) thoracotomy in 71 patients resulting in thirteen patients $(18 \%)$ to survive after additional treatment in a trauma centre. All survivors $(n=13)$ had a cardiac tamponade and a ventricular $(n=12)$ or aortic $(n=1)$ wound [70]. Clamshell incision (CI) may be a superior approach over left anterolateral thoracotomy since it offers better exposure and does not take more time for inexperienced physicians performed in a cadaver model for surgical residents [73]. In the prehospital case series reported by Coats et al. and Davies et al. RT was exclusively done via CI [70, 74]. Morrison et al. stated that pre-hospital thoracotomy in the military setting is futile with an estimated $0.7 \%$ survival for patients with multiple gunshot wounds [75]. A case series of 34 prehospital thoracotomies in blunt trauma by Japanese HEMS showed no survivors [72]. A recent systematic review on emergency department resuscitative thoracotomy (EDT) in Europe showed a far more favourable survival rate of 12.9 \% (18 out of 139) in blunt and $41.6 \%$ (37 out of 89 ) in penetrating injuries [76].

Guidelines by the European Resuscitation Council (ERC) and Eastern Association for the surgery of Trauma (EAST) strongly recommend RT after penetrating trauma with witnessed signs of life (SoL) or ECG activity after short-term, and conditionally recommend RT in penetrating trauma without these features. In blunt trauma without witnessed SoL, RT is considered futile. Patients with blunt trauma with vital SoL and witnessed cardiac arrest RT can be performed. Nevertheless, in this 'favourable' group of blunt trauma patients the outcome is poor with an estimated survival rate of $1.6 \%[77,78]$.

\section{Intra-abdominal haemorrhage}

Traumatic intra-abdominal haemorrhage is challenging due to the variety of organs and vessels possibly ruptured or penetrated. Rapid surgical intervention is currently the only option to stop the bleeding in case of catastrophic abdominal haemorrhage [79]. Resuscitative thoracotomy (RT) with cross-clamping of the thoracic aorta is a radical intervention in case of imminent circulatory arrest due to abdominal bleeding [65, 80,81]. Successful case series of this intervention in the prehospital situation have been described by the London HEMS [70, 71] and by Madrid's SAMUR-Protección Civil [66]. A laparotomy in the field is not feasible since the source of the bleeding is unknown, surgical expertise is absent and no operating theatre can be realised. In order to reduce the rate of prehospital 
exsanguination, research into further interventions to stop intra-abdominal bleeding are warranted [54, 82, 83].

\section{Intra-abdominal haemorrhage - gas insufflation}

Animal studies showed reduced blood loss by raising abdominal pressure by gas insufflation in case of hepatic $[84,85]$, splenic $[86,87]$ and inferior vena cava bleeding [88]. See Table 1. Kasotakis et al. described the possibility to use this technique en-route by using a portable carbon dioxide insufflator [87]. No clinical studies were identified for this review.

\section{Intra-abdominal haemorrhage - self-expanding foam}

Another invention to counter intra-abdominal haemorrhage is to inject biocompatible self-expanding foam intraperitoneally. This foam expands, engulfs the organs and becomes solid, thereby tamponading the bleeding. So far several animal studies have been executed in hepatoportal [82, 83, 89, 90], splenic [91] and iliac artery [92] models of intra-abdominal haemorrhage. See Table 1. Localized enteric pressure necrosis has been reported as frequent complication, requiring seromuscular sutures or resection [91]. Rago et al. stated that in a survey of 3442 injured soldiers in the Operation Iraqi Freedom suffering intra-abdominal bleeding, $34 \%$ of patients required bowel repair and $19 \%$ even resection anyway, so the localized necrosis might be considered an acceptable complication in patients facing imminent exsanguination [91, 93]. In July 2015, Mesar et al., published a study on the optimal human dosage by injecting the foam in recently deceased humans [94]. At the time of this review, no clinical use of ResQFoam $^{\text {Ts }}$ (Arsenal Medical, Watertown MA) has been published.

\section{Intra-abdominal haemorrhage - REBOA}

The previously described REBOA can also be applied to thoracic zone (Zone I), thereby occluding abdominal aortic flow in case of intra-abdominal haemorrhage. REBOA is considered to be far less invasive compared to a thoracotomy with descendent aortic cross clamping [95]. It has been assessed in various animal models $[57,58,63,96]$. as well as in the clinical setting [54, 61, 62, 97]. See Table 1. Ogura et al. published a case series of patients $(n=8)$ with haemoperitoneum after blunt abdominal trauma with a successful in-hospital REBOA in $86 \%(n=7)$ [97]. Moore et al. reported a lower mortality rate for in-hospital REBOA $(n=24)$ vs resuscitative thoracotomy $(n=72)$ in non-compressible truncal haemorrhage: $62.5 \%$ vs $90.3 \%$. Injury Severity Score did not differ significantly. However, in the RT-group a higher percentage received cardiopulmonary resuscitation (CPR) upon arrival [62]. Analysing patients from the Japanese trauma data bank who received an in-hospital REBOA, Norii et al. found a higher mortality in patients receiving a REBOA compared to those who did not, even after correction for injury pattern and other variables. This might be explained by REBOA being used as a 'last ditch' effort. Interestingly, REBOA is part of the Japanese emergency physicians arsenal since trauma surgeons are not always attending 24/7 [98].

\section{Intra-abdominal haemorrhage - aortic abdominal and junctional tourniquet $(A A J T)^{\mathrm{Tm}}$}

The AAJT ${ }^{\mathrm{Tm}}$ has not been reported for abdominal bleeding, however when no other options are available, its use might be feasible since it has the ability to restrict the intraabdominal compartment by external pressure, theoretically providing an earlier tamponade of the abdominal cavity. Nevertheless, abdominal application is contra-indicated in the case of penetrating injury [46].

\section{Pelvic haemorrhage}

Pelvic fracture, or the so-called 'the killing fracture' [99], is potential lethal, especially in severe pelvic disruption with following haemorrhagic shock [100]. Mortality of traumatic pelvic injury is estimated at $28 \%$ by Papakostidis et al. in a recent systematic review [101]. Haemodynamic instability is present in $10 \%$ of pelvic fractures [102], and often the origin of the bleeding is uncertain: it may be caused by (a combination of) bleeding from fracture surfaces, the venous plexus or arteries [103].

A study of 5340 German trauma patients with a pelvic fracture showed a mortality of $4 \%$ (238 patients). In these deceased patients, massive haemorrhage was the cause of death in $34 \%$, of which $62 \%$ was specified to the pelvic region. Holstein et al. did not include prehospital mortality, so the mortality rate due to exsanguination is likely to be even higher [104].

\section{Pelvic haemorrhage - circumferential binders}

Several devices providing circumferential pressure are on the market [103], if not equipped with such a device a conventional sheet should be applied [105]. Placing a circumferential binder $(\mathrm{CB})$ or sheet will reduce the volume of the intra-pelvic cavity, compress the fracture surfaces and prevent dislodgement of newly formed clots by preventing second displacement [106].

Tan et al. reported a reduced symphyseal diastasis of $60 \%$ in unstable pelvic fractures after emergency department application of a Trauma Pelvic Orthotic Device ${ }^{\text {ma }}$ (T-POD ${ }^{\mathrm{mw}}$, Pyng Medical, Richmond Canada) and a rise in mean arterial pressure form 65.3 to 81.2 [107]. Croce et al. stated that the implementation of the T-POD ${ }^{\mathrm{max}}$ significantly reduced transfusion requirement ( 9.9 vs 21.5 units) and length of stay (16.5 vs $24 . .4$ days) [108]. The SAM-sling ${ }^{\text {Tx }}$ (SAM Medical Products, Oregon, USA) is an alternative, and was tested clinically by Krieg et al. in 16 patients with a pelvic ring injury upon arrival at the 
ED resulting in an $9.9 \%$ reduction of the pelvic distension [109]. The PelvicBinder ${ }^{\mathrm{TM}}$ (PelvicBinder Inc., Dallas, USA) has been reported to be superior over sheet wrapping for emergency stabilisation of the pelvis [110]. Knops et al. found all of the three commercial temporary pelvic stabilizers providing sufficient reduction in of the pelvic fracture in a cadaveric study, with the T-POD requiring the lowest force [111].

If the patient haemodynamically further deteriorates, despite application of a CB, an arterial origin is suspected [112]. The CB should be left in place, and an $\mathrm{AAJT}^{\mathrm{TM}}$ can be placed at the umbilical region to externally compresses the abdominal aorta to the spine, prohibiting distal arterial flow to the pelvis and lower extremities. Taylor et al. reported successful aortic occlusion in 15 of 16 voluntary soldiers by Doppler sound examination of the common femoral artery [46].

\section{Pelvic haemorrhage- REBOA}

REBOA in uncontrolled pelvic haemorrhage is of great interest and both preclinical [113-115] and clinical publications on this topic are vast [54,60-62, 116]. See Table 1. As the iliac artery is on the route of the REBOA placement, unilateral femoral pulsation is required. An in-hospital series of 13 cases of uncontrollable haemorrhage due to pelvic injury the use of REBOA led to initial haemorrhage control in 12 patients. Deflation of the balloon in the angiographic suite resulted in recurrence of haemodynamic instability in half of the patients. Ultimately 6 of the initial patients survived to discharge. The Injury Severity Scores (ISS) differed among survivors and non-survivors (ISS 38 versus $58, p=0.011$ ) but the Revised Trauma Score did not: 4.362 versus 4.779, $p=0.761$ [60]. Brenner et al. reported ED deployment of REBOA within 6 min (range 4-6) in a series of 6 patients (5 cases of pelvic fracture and 1 patient with a renal injury). Two patients did not survive due to concomitant brain injury and non-survivable injuries [54]. The London HEMS in 2014 reported the first pre-hospital performed REBOA in a patient with a pelvic fracture with a successful control of the bleeding bridging transport to definitive care [116].

\section{Discussion}

This study provides an overview of established, novel and future prehospital treatment options in care for trauma patients with exsanguinating truncal or junctional haemorrhage. Some options have been incorporated in protocols worldwide, i.e., temporary pelvic stabilizers [105], as others, such as REBOA [117], have regained new interest after they were previously abandoned. Throughout history, war necessitated innovative medical improvements $[28,118]$. The development of junctional tourniquets, for instance, is the result of changes in injury patterns in the current conflicts. An increase of blast injuries from improvised explosive devices (IED's) resulted in a combination of pelvic fracture, traumatic lower limb amputations and torso injuries [119] requiring more proximal haemorrhage control than can be provided by extremity tourniquets [33].

Unfortunately, nowadays civilians in western societies are increasingly victim of penetrating trauma due to shootings, stabbings and bombings. Especially in mass casualty scenarios from recent (terrorist) attacks, victims show injury patterns that resemble those in the military setting [120, 121]. Evaluation of the 2013 Boston Marathon bombing revealed that knowledge from the military (i.e., the use of an extremity tourniquet) was not yet translated to civilian prehospital trauma care and that further progress is desirable [122]. Recently the Hartford Consensus promotes application of tourniquets and usage of haemostatic gauze dressings by non-(para) medical responders and lay persons to stop bleeding early [29-31].

As many of the novelties described were developed from a military medicine point of view experience, it is worthwhile to discuss whether the innovations might be useful for the civilian prehospital arena [28, 123]. Military prehospital care may differ from civilian prehospital care in several ways: patient population, trauma mechanism, on-going gunfire, remoteness and skill level of care providers. Combat casualties sustain a much higher ratio of penetrating and blast injuries in contrast to the mainly blunt injuries in civilian patients. However, soldiers are likely to be fitter than the average civilian population, and more able to compensate in case of haemorrhagic shock. In general, EMS teams encounter less hostile working circumstances than military medics [123]. Furthermore, extraction time and/or transport to the nearest facility for damage control (forward surgical team facility) in general takes longer than in the civilian situation (trauma centre). However, in the setting of civilian cases in remote and/or rural area's rescue and transport times are usually prolonged mimicking the military situation [124]. So, in these cases when confronted with massive haemorrhage, achieving early haemorrhage control on scene or during transport might result in a better chance at survival when the nearest adequate definitive care facility is obvious too far away to justify 'scoop and run' $[2,6,125]$. Moreover, it may not be feasible to maintain direct pressure (as primary treatment of junctional bleeding) during evacuation. In a study on the feasibility of manual pressure, 44 clinicians had to provide bimanual compression at a maintainable effort: mean pressure was $39 \mathrm{~kg}$ (range 17-60). This was found to be insufficient to occlude flow in the iliac and abdominal aortic artery which required pressure of $54 \mathrm{~kg}$ and $63 \mathrm{~kg}$ respectively [126].

A 2015 survey on the translation of innovations in military medicine to civilian practice revealed military 
experience was of importance to implementation of massive transfusion protocol (63\%), tourniquets (60\%) and haemostatic gauzes (41\%) in US civilian trauma systems. Overall, inventions proven effective in military medicine were considered effective 'most of the time' (52\%) or 'always' (10 \%) in the civilian setting! However, civilian research confirming military data on the inventions was considered insufficient [28].

High quality clinical studies in the population of haemorrhagic trauma patients in extremis are clearly difficult to conduct. Preclinical studies in a standardized model, such as the swine model described by Kheirabadi et al. [127], should form the basis for the development of new adjuncts. For non-invasive options (i.e., junctional tourniquets), testing in a simulation model in volunteers would be the next step [43]. Feedback from the field in small pilot studies by military or prehospital civilian care-providers will provide for further direction of development [33, 43]. As pointed out by Haider et al. collaboration of civilian and military physicians is essential provide evidence in how life-threatening haemorrhage can be dealt with in the (chaotic) prehospital arena [28].

Several interventions discussed in this review require high skill level of the prehospital care provider. For the performance of prehospital REBOA or prehospital resuscitative thoracotomy, a physician-staffed prehospital team is required. Application of junctional tourniquets, iTClamps $^{\mathrm{Tm}}, \mathrm{X}$-stat ${ }^{\mathrm{Tm}}$, pelvic circumferential binders and topical haemostatics can be applied by trained EMS paramedics. Possible future options as intra-abdominal insufflation or self-expanding foam may be appropriate to be used by paramedics.

Successful implementation of interventions for truncal and/or junctional bleeding in civilian prehospital care systems requires (trauma) surgical leadership or similar involvement. Careful study of the efficacy of the concerned interventions is mandated but literature is yet limited to small case series. Analysis of the prehospital trauma patient population (in the EMS catchment area) is mandated regarding trauma mechanism, incidence of massive haemorrhage, rescue and transport time to assess the meaningfulness of implementation of a certain intervention. For instance, in case of an urban system, short (i.e., less than $15 \mathrm{~min}$ ) transport times to definitive care facilities may deem interventions as REBOA unwanted but this may not be the case when the victim has to be retrieved from a remote area. Nevertheless even in an urban system definitive care can be delayed by longer prehospital times caused by entrapment, confinement or even heavy traffic. Also, e.g., in a rare civilian case of junctional bleeding, direct pressure (when enough personnel available) during transport might be the best option instead of training and equipping all ambulance personnel and ambulances with junctional tourniquets. There are no data on patients that might have had a hypothetical benefit from prehospital junctional and truncal haemorrhage control in civilian context situation so the incidence, from the in-hospital point of view point, seem low. Nevertheless, from a conceptual point of view, early haemorrhage control is of vital importance. Advanced prehospital haemorrhage control (i.e., junctional tourniquets, REBOA, resuscitative thoracotomy, etc.) may be considered as an additional expert task for physician-staffed EMS when timely dispatched to the patient at the scene or the ambulance; diminishing blood loss and transfusion requirements.

The trade-off of a more aggressive prehospital haemorrhage control system with the use of the retrieved adjuncts is the concomitant consequence of side-effects and/or complications. See Table 2. Since the devices are designed to stop bleeding, ischaemia is an important complication. $\mathrm{X}$-stat and the junctional tourniquets have to be removed within $4 \mathrm{~h}$ after application [33, 35]. The truncal placement of the AAJT has an ultimatum of one hour $[44,46]$. Due to the large pressure the AAJT effectuates over the abdomen, some effect on ventilation may occur [33]. REBOA has a serious risk of spinal or mesenteric ischaemia and therefore application has to be as short (20-40 min) as possible [61, 96, 117].

Life-threatening haemorrhage from extremities has been impressively tackled by prehospital application of extremity tourniquets, and focus will shift to stop junctional and truncal haemorrhage. This review aimed to provide an comprehensive overview of established, stateof-the-art and future strategies to arrest catastrophic haemorrhage in order to bridge time to definitive care in patients who formerly died of exsanguination prior to reaching a trauma centre. Unfortunately the level of evidence is extremely limited, but awareness of potentially life-saving novelties is a first step to encounter the increasing threat of exsanguination from combat-like injuries in the civilian arena. Indiscriminate implementation of the discussed interventions is not advisable since there is scarce data on potential harmful side-effects (e.g., due to ischaemia). Moreover, one should be aware of the risk of "indication gliding" which is seen in many other medical fields - a device developed for life-threatening situation start being used in less injured patients, and the risk of side-effects become more important.

\section{Conclusion}

Control of bleeding from junctional areas and noncompressible torso bleeding remains the greatest challenge in prehospital trauma care. Junctional tourniquets, resuscitative thoracotomy, REBOA, pelvic circumferential binders and the iTClamp ${ }^{\text {tw }}$ have been developed. Injury pattern and transport time to definitive care differs significantly 
Table 2 List of identified prehospital treatment options

\begin{tabular}{|c|c|c|c|c|c|}
\hline Class & Adjunct & Name & Manufacturier & Pro's & Con's \\
\hline \multirow[t]{4}{*}{$\begin{array}{l}\text { Junctional } \\
\text { tourniquets }\end{array}$} & $\mathrm{CRoC}^{\mathrm{TM}}$ & $\begin{array}{l}\text { Combat Ready } \\
\text { Clamp }^{\mathrm{TM}}\end{array}$ & $\begin{array}{l}\text { Combat medical systems. } \\
\text { Fayetteville, NC }\end{array}$ & Easy. $4 \mathrm{~h}$ max & $\begin{array}{l}\text { Dislodgement, heavy, limb } \\
\text { ischemia, longer application } \\
\text { time than other JT's }\end{array}$ \\
\hline & JETT ${ }^{\mathrm{TM}}$ & $\begin{array}{l}\text { Juntional Emergency } \\
\text { Tourniquet Tool }{ }^{\mathrm{TM}}\end{array}$ & $\begin{array}{l}\text { North American Rescue } \\
\text { Products. Greer, SC }\end{array}$ & Easy. 4 h max. Stabilizes pelvis & No reports of clinical use \\
\hline & SAM-JTM & $\begin{array}{l}\text { SAM Junctional } \\
\text { Tourniquet }^{\text {TM }}\end{array}$ & $\begin{array}{l}\text { SAM Medical Products. } \\
\text { Wilsonville, OR }\end{array}$ & Easy. 4 h max. Stabilizes pelvis & Little experience \\
\hline & AAJT'M & $\begin{array}{l}\text { Abdominal Aortic } \\
\text { and Junctional } \\
\text { Tourniqet }{ }^{\mathrm{M}}\end{array}$ & $\begin{array}{l}\text { Compression Works. } \\
\text { Hoover, AL }\end{array}$ & $\begin{array}{l}\text { Axillary, inguinal and truncal } \\
\text { application. External } \\
\text { compression of the } \\
\text { abdominal aorta }\end{array}$ & $\begin{array}{l}\text { Easily broken. Uncomfortable } \\
\text { in truncal application. Truncal } \\
\text { max } 1 \mathrm{~h} \text {. In penetrating trauma } \\
\mathrm{Cl} \text { for truncal placement }\end{array}$ \\
\hline Wound clamp & $\mathrm{iTC}^{\mathrm{TM}}$ & iTClamp ${ }^{\mathrm{TM}}$ & $\begin{array}{l}\text { Innovative Trauma Care. } \\
\text { San Antonio, TX }\end{array}$ & Very easy, any location & Only superficial seal, hematoma \\
\hline $\begin{array}{l}\text { Haemostatic } \\
\text { agent }\end{array}$ & XStat-30 & XStat-30 & RevMedx. Wilsonville, OR & $\begin{array}{l}\text { Easy, tailored for deep } \\
\text { penetrating wounds }\end{array}$ & $\begin{array}{l}\text { Only junctional, removal of } \\
\text { sponges }\end{array}$ \\
\hline \multirow[t]{2}{*}{ REBOA } & 9-14 Fr & $\begin{array}{l}\text { Coda }^{\mathrm{TM}} \text { Balloon } \\
\text { Catheter }\end{array}$ & $\begin{array}{l}\text { Cook Medical, Indianapolis, } \\
\text { IN }\end{array}$ & \multirow[t]{2}{*}{$\begin{array}{l}\text { Proximal control, raises } \\
\text { central aortic pressure }\end{array}$} & \multirow{2}{*}{$\begin{array}{l}\text { Invasive, requires physician, risk } \\
\text { at (spinal) ischemia, challenging, } \\
\text { time consuming }\end{array}$} \\
\hline & $7 \mathrm{Fr}$ & ER-REBOA ${ }^{\mathrm{TM}}$ & Pryor Medical. Arvada, CO & & \\
\hline $\begin{array}{l}\text { Intra-abdominal } \\
\text { gas insufflation }\end{array}$ & - & - & - & $\begin{array}{l}\text { Minor invasive. Less risk at } \\
\text { pressure necrosis than foam. }\end{array}$ & $\begin{array}{l}\text { Abdominal compartment } \\
\text { syndrome, risk of air embolisms, } \\
\text { experimental }\end{array}$ \\
\hline $\begin{array}{l}\text { Intra-abdominal } \\
\text { self-expanding } \\
\text { foam }\end{array}$ & ResQFoam $^{\mathrm{TM}}$ & ResQFoam ${ }^{\text {TM }}$ & $\begin{array}{l}\text { Arsenal Medical. Waterland, } \\
\text { MA }\end{array}$ & $\begin{array}{l}\text { Tamponade of abdominal } \\
\text { compartment, less invasive } \\
\text { then RT/REBOA, no physician } \\
\text { required }\end{array}$ & $\begin{array}{l}\text { Pressure necrosis, abdominal } \\
\text { compartment syndrome, needs } \\
\text { surgical removal, experimental }\end{array}$ \\
\hline \multirow[t]{3}{*}{ Pelvic stabilizer } & T-POD ${ }^{\mathrm{TM}}$ & $\begin{array}{l}\text { Trauma Pelvic } \\
\text { Orthotic Device }\end{array}$ & $\begin{array}{l}\text { Pyng Medical. Richmond, } \\
\text { Canada }\end{array}$ & \multirow{3}{*}{$\begin{array}{l}\text { Easy applicable, wide } \\
\text { experience, enables } \\
\text { REBOA/AAJT }\end{array}$} & \multirow[t]{3}{*}{$\begin{array}{l}\text { Insufficient if origin of } \\
\text { haemorrhage is arterial }\end{array}$} \\
\hline & SAM-sling ${ }^{T M}$ & SAM-sling ${ }^{\mathrm{TM}}$ & $\begin{array}{l}\text { SAM Medical Products. } \\
\text { Wilsonville, OR }\end{array}$ & & \\
\hline & PelvicBinder ${ }^{\mathrm{TM}}$ & PelvicBinder ${ }^{\mathrm{TM}}$ & PelvicBinder Inc. Dallas, TX & & \\
\hline Pelvic Sheet & - & - & - & Low cost, widely available & $\begin{array}{l}\text { Inadequate application, } \\
\text { dislodgement }\end{array}$ \\
\hline $\begin{array}{l}\text { Resuscitative } \\
\text { Thoracotomy }\end{array}$ & - & - & - & $\begin{array}{l}\text { Very proximal control, raises } \\
\text { central aortic pressure. }\end{array}$ & $\begin{array}{l}\text { Invasive, risk at infection, } \\
\text { requires physician }\end{array}$ \\
\hline
\end{tabular}

between combat care and civilian trauma care. In case of bomb attacks, stabbings, mass shootings, civilian prehospital situations resemble military settings. The use of military inventions such as tourniquets and haemostatic gauze dressings have been successfully translated to the civilian situation. The focus of research will now probably shift to stopping junctional and truncal bleeding. Several promising treatment options have been developed, but overall the level of evidence of the included studies is extremely low.

\footnotetext{
Abbreviations

AAT: Abdominal aortic and junctional tourniquet; AAT: Abdominal aortic tourniquet; CAP: Central aortic pressure; CB: Circumferential binder; CRoC: Combat ready clamp; EAST: Eastern Association for the surgery of Trauma; ED: Emergency department; EDT: Emergency department thoracotomy; EMS: Emergency medical service; ERC: European resuscitation council; HEMS: Helicopter emergency medical service; IED: Improvised explosive device; ISS: Injury severity score; ITC: iTClamp; JETT: Junctional emergency tourniquet tool; REBOA: Resuscitative endovascular balloon occlusion of the aorta; RT: Resuscitative thoracotomy; SAM-JT: SAM junctional tourniquet; SOL: Signs of life
}

\section{Acknowledgements}

Figures 2, 3, 4 and 5 provided by the courtesy of the manufacturers.

\section{Funding}

No funding was received.

\section{Availability of data and materials \\ Not applicable.}

\section{Authors' contributions}

SvO was responsible for the search, data collection, data interpretation and syntheses of the manuscript. ET has contributed in terms of data interpretation and revision of the manuscript. LG was responsible for the design of this review, data interpretation and final revision of the manuscript Acknowledgements are not applicable. All authors read and approved the final manuscript.

\section{Competing interests}

The authors declare that they have no competing interests.

\section{Consent for publication}

Not applicable.

Ethics approval and consent to participate Not applicable. 


\section{Author details}

'Department of Trauma Surgery, VU University Medical Center, P.O. Box 7057 1007 MB Amsterdam, The Netherlands. ${ }^{2}$ Department of Trauma Surgery and Helicopter Emergency Medical Service, Radboud University Medical Center, Nijmegen, The Netherlands. ${ }^{3}$ Royal Netherlands Army, Utrecht, The Netherlands.

Received: 28 June 2016 Accepted: 1 September 2016

Published online: 13 September 2016

\section{References}

1. Bellamy RF. The causes of death in conventional land warfare: implications for combat casualty care research. Mil Med. 1984;149:55-62

2. Eastridge BJ, Mabry RL, Seguin P, Cantrell J, Tops T, Uribe P, et al. Death on the battlefield (2001-2011): implications for the future of combat casualty care. J Trauma Acute Care Surg. 2012;73:S431-7.

3. Tien HC, Spencer F, Tremblay LN, Rizoli SB, Brenneman FD. Preventable deaths from hemorrhage at a level I Canadian trauma center. J Trauma. 2007;62:142-6

4. Teixeira PGR, Inaba K, Hadjizacharia P, Brown C, Salim A, Rhee P, et al. Preventable or potentially preventable mortality at a mature trauma center. J Trauma. 2007;63:1338-46.

5. Sauaia A, Moore FA, Moore EE, Moser KS, Brennan R, Read RA, et al. Epidemiology of trauma deaths: a reassessment. J Trauma. 1995;38:185-93.

6. Chaudery M, Clark J, Wilson MH, Bew D, Yang GZ, Darzi A. Traumatic intra-abdominal hemorrhage control: has current technology tipped the balance toward a role for prehospital intervention? J Trauma Acute Care Surg. 2015;78:153-63.

7. Malone DL, Dunne J, Tracy JK, Putnam AT, Scalea TM, Napolitano LM. Blood transfusion, independent of shock severity, is associated with worse outcome in trauma. J Trauma. 2003:54:898-905.

8. Kauvar DS, Lefering R, Wade CE. Impact of hemorrhage on trauma outcome: an overview of epidemiology, clinical presentations, and therapeutic considerations. J Trauma. 2006;60:\$3-11.

9. Geeraedts LMGJ, Kaasjager $H A H$, van Vugt $A B$, Frolke JPM. Exsanguination in trauma: a review of diagnostics and treatment options. Injury. 2009:40:11-20.

10. (NAEMT) NAoEMT. PHTLS: Prehospital Trauma Life Support, 8th Edition. 8th Revised edition ed. Sudbury, United States: Jones and Barlett Publishers, Inc; 2015.

11. Beekley AC, Sebesta JA, Blackbourne LH, Herbert GS, Kauvar DS, Baer DG, et al. Prehospital tourniquet use in operation Iraqi freedom: effect on hemorrhage control and outcomes. J Trauma. 2008;64:S28-37.

12. Kragh JFJ. Use of tourniquets and their effects on limb function in the modern combat environment. Foot Ankle Clin. 2010;15:23-40.

13. Inaba K, Siboni S, Resnick S, Zhu J, Wong MD, Haltmeier T, et al. Tourniquet use for civilian extremity trauma. J Trauma Acute Care Surg. 2015;79:232-7.

14. Kue RC, Temin ES, Weiner SG, Gates J, Coleman MH, Fisher J, et al. Tourniquet use in a civilian emergency medical services setting: a descriptive analysis of the Boston EMS experience. Prehosp Emerg Care. 2015;19:399-404

15. Schroll R, Smith A, McSwain Jr NE, Myers J, Rocchi K, Inaba K, et al. A multi-institutional analysis of prehospital tourniquet use. J Trauma Acute Care Surg. 2015;79:10-4.

16. Ode G, Studnek J, Seymour R, Bosse MJ, Hsu JR. Emergency tourniquets for civilians: can military lessons in extremity hemorrhage be translated? J Trauma Acute Care Surg. 2015;79:586-91.

17. Dean NR, Ledgard JP, Katsaros J. Massive hemorrhage in facial fracture patients: definition, incidence, and management. Plast Reconstr Surg. 2009;123:680-90

18. Rezende-Neto J, Marques AC, Guedes LJ, Teixeira LC. Damage control principles applied to penetrating neck and mandibular injury. J Trauma. 2008;64:1142-3.

19. Arne BC. Management of scalp hemorrhage and lacerations. J Spec Oper Med. 2012:12:11-6.

20. Fitzpatrick MO, Seex K. Scalp lacerations demand careful attention before interhospital transfer of head injured patients. J Accid Emerg Med. 1996;13:207-8

21. Lemos MJ, Clark DE. Scalp lacerations resulting in hemorrhagic shock: case reports and recommended management. J Emerg Med. 1988;6:377-9.
22. Granville-Chapman J, Jacobs N, Midwinter MJ. Pre-hospital haemostatic dressings: a systematic review. Injury. 2011:42:447-59.

23. Bennett BL, Littlejohn LF, Kheirabadi BS, Butler FK, Kotwal RS, Dubick MA et al. Management of external hemorrhage in tactical combat casualty care: Chitosan-Based Hemostatic Gauze Dressings - TCCC GuidelinesChange 13-05. J Spec Oper Med. 2014;14:40-57.

24. Smith AH, Laird C, Porter K, Bloch M. Haemostatic dressings in prehospital care. Emerg Med J. 2013;30:784-9.

25. Zietlow JM, Zietlow SP, Morris DS, Berns KS, Jenkins DH. Prehospital use of hemostatic bandages and tourniquets: translation from military experience to implementation in civilian trauma care. J Spec Oper Med. 2015;15:48-53.

26. Travers S, Lefort $H$, Ramdani E, Lemoine S, Jost D, Bignand $M$, et al. Hemostatic dressings in civil prehospital practice: 30 uses of QuikClot Combat Gauze. Eur J Emerg Med. 2016;23:391-4.

27. Bulger EM, Snyder D, Schoelles K, Gotschall C, Dawson D, Lang E, et al. An evidence-based prehospital guideline for external hemorrhage control: American College of Surgeons Committee on Trauma. Prehosp Emerg Care. 2014;18:163-73

28. Haider AH, Piper LC, Zogg CK, Schneider EB, Orman JA, Butler FK, et al. Military-to-civilian translation of battlefield innovations in operative trauma care. Surgery. 2015;158:1686-95.

29. Jacobs LM, Wade DS, MCSwain NE, Butler FK, Fabbri WP, Eastman AL, et al. The Hartford Consensus: THREAT, a medical disaster preparedness concept. J Am Coll Surg. 2013;217:947-53.

30. Jacobs LM, Wade D, McSwain NE, Butler FK, Fabbri W, Eastman A, et al. Hartford Consensus: a call to action for THREAT, a medical disaster preparedness concept. J Am Coll Surg. 2014;218:467-75.

31. Pons PT, Jerome J, McMullen J, Manson J, Robinson J, Chapleau W. The Hartford Consensus on active shooters: implementing the continuum of prehospital trauma response. J Emerg Med. 2015:49:878-85.

32. Manual of Definitive Surgical Trauma Care. 4th ed. CRC Press; 2015. https://www.crcpress.com/Manual-of-Definitive-Surgical-Trauma-CareFourth-Edition/Boffard/p/book/9781498714877

33. Kotwal RS, Butler FK, Gross KR, Kheirabadi BS, Baer DG, Dubick MA, et al. Management of junctional hemorrhage in tactical combat casualty care: TCCC guidelines?proposed change 13-03. J Spec Oper Med. 2013;13:85-93.

34. Kragh Jr JF, Aden JK, Steinbaugh J, Bullard M, Dubick MA. Gauze vs XSTAT in wound packing for hemorrhage control. Am J Emerg Med. 2015;33:974-6.

35. FDA. XStat-30. 2015

36. Maclntyre AD, Quick JA, Barnes SL. Hemostatic dressings reduce tourniquet time while maintaining hemorrhage control. Am Surg. 2011;77:162-5.

37. Kragh JFJ, Johnson JE, Henkel CK, Dubick MA. Technique of axillary use of a Combat Ready Clamp to stop junctional bleeding. Am J Emerg Med. 2013;31:1274-6

38. Kheirabadi BS, Terrazas IB, Hanson MA, Kragh JFJ, Dubick MA, Blackbourne LH. In vivo assessment of the Combat Ready Clamp to control junctional hemorrhage in swine. J Trauma Acute Care Surg. 2013:74:1260-5.

39. Croushorn J, Thomas G, McCord SR. Abdominal aortic tourniquet controls junctional hemorrhage from a gunshot wound of the axilla. J Spec Oper Med. 2013;13:1-4

40. Lyon M, Johnson D, Gordon R. Use of a Novel Abdominal Aortic and Junctional Tourniquet to Reduce or Eliminate Flow in the Brachial and Popliteal Arteries in Human Subjects. Prehosp Emerg Care. 2015;19:405-8.

41. Kirkpatrick AW, McKee JL. Tactical Hemorrhage Control Case Studies Using a Point-of-Care Mechanical Direct Pressure Device. J Spec Oper Med. 2014;14:7-10.

42. Tan ECTH, Peters JH, Mckee JL, Edwards MJR. The iTClamp in the management of prehospital haemorrhage. Injury. 2016;47(5):1012-5. doi:10.1016/j.injury.2015.12.017. Epub 29 Dec 2015.

43. Kragh JFJ, Parsons DL, Kotwal RS, Kheirabadi BS, Aden JK, Gerhardt RT, et al. Testing of junctional tourniquets by military medics to control simulated groin hemorrhage. J Spec Oper Med. 2014;14:58-63.

44. Lyon M, Shiver SA, Greenfield EM, Reynolds BZ, Lerner EB, Wedmore IS, et al. Use of a novel abdominal aortic tourniquet to reduce or eliminate flow in the common femoral artery in human subjects. J Trauma Acute Care Surg. 2012:73:S103-5.

45. Tovmassian RV, Kragh JFJ, Dubick MA, Baer DG, Blackbourne LH. Combat ready clamp medic technique. J Spec Oper Med. 2012:12:72-8.

46. Taylor DM, Coleman M, Parker PJ. The evaluation of an abdominal aortic tourniquet for the control of pelvic and lower limb hemorrhage. Mil Med. 2013;178:1196-201. 
47. Gates KS, Baer L, Holcomb JB. Prehospital emergency care: evaluation of the junctional emergency tourniquet tool with a perfused cadaver model. J Spec Oper Med. 2014;14:40-4.

48. Klotz JK, Leo M, Anderson BL, Nkodo AA, Garcia G, Wichern AM, et al. First case report of SAM? Junctional tourniquet use in Afghanistan to control inguinal hemorrhage on the battlefield. J Spec Oper Med. 2014;14:1-5.

49. Anonymous. Abdominal aortic tourniquet? Use in afghanistan. J Spec Oper Med. 2013;13:1-2.

50. Croushorn J. Abdominal aortic and junctional tourniquet controls hemorrhage from a gunshot wound of the left groin. J Spec Oper Med. 2014;14:6-8.

51. Filips D, Logsetty S, Tan J, Atkinson I, Mottet K. The iTClamp controls junctional bleeding in a lethal swine exsanguination model. Prehosp Emerg Care. 2013;17:526-32.

52. Mottet K, Filips D, Logsetty S, Atkinson I. Evaluation of the iTClamp 50 in a human cadaver model of severe compressible bleeding. J Trauma Acute Care Surg. 2014;76:791-7.

53. Barnung S, Steinmetz J. A prehospital use of ITClamp for haemostatic control and fixation of a chest tube. Acta Anaesthesiol Scand. 2014;58:251-3.

54. Brenner ML, Moore LJ, DuBose JJ, Tyson GH, McNutt MK, Albarado RP, et al. A clinical series of resuscitative endovascular balloon occlusion of the aorta for hemorrhage control and resuscitation. J Trauma Acute Care Surg. 2013; 75:506-11.

55. HUGHES CW. Use of an intra-aortic balloon catheter tamponade for controlling intra-abdominal hemorrhage in man. Surgery. 1954;36:65-8.

56. Gupta BK, Khaneja SC, Flores L, Eastlick L, Longmore W, Shaftan GW. The role of intra-aortic balloon occlusion in penetrating abdominal trauma. J Trauma. 1989:29:861-5.

57. Long KN, Houston R, Watson JD, Morrison JJ, Rasmussen TE, Propper BW, et al. Functional outcome after resuscitative endovascular balloon occlusion of the aorta of the proximal and distal thoracic aorta in a swine model of controlled hemorrhage. Ann Vasc Surg. 2015;29:114-21.

58. Morrison JJ, Ross JD, Houston R, Watson JD, Sokol KK, Rasmussen TE. Use of resuscitative endovascular balloon occlusion of the aorta in a highly lethal model of noncompressible torso hemorrhage. Shock. 2014;41:130-7.

59. Stannard A, Eliason JL, Rasmussen TE. Resuscitative endovascular balloon occlusion of the aorta (REBOA) as an adjunct for hemorrhagic shock. J Trauma. 2011;71:1869-72

60. Martinelli T, Thony F, Declety P, Sengel C, Broux C, Tonetti J, et al. Intraaortic balloon occlusion to salvage patients with life-threatening hemorrhagic shocks from pelvic fractures. J Trauma. 2010;68:942-8.

61. Saito N, Matsumoto H, Yagi T, Hara Y, Hayashida K, Motomura T, et al. Evaluation of the safety and feasibility of resuscitative endovascular balloon occlusion of the aorta. J Trauma Acute Care Surg. 2015;78:897-903.

62. Moore LJ, Brenner M, Kozar RA, Pasley J, Wade CE, Baraniuk MS, et al. Implementation of resuscitative endovascular balloon occlusion of the aorta as an alternative to resuscitative thoracotomy for noncompressible truncal hemorrhage. J Trauma Acute Care Surg. 2015;79:523-30.

63. Russo RM, Williams TK, Grayson JK, Lamb CM, Cannon JW, Clement NF, et al. Extending the golden hour: Partial resuscitative endovascular balloon occlusion of the aorta (P-REBOA) in a highly lethal swine liver injury model. J Trauma Acute Care Surg. 2016;80(3):372-8.

64. Chaudery M, Clark J, Morrison JJ, Wilson MH, Bew D, Darzi A. Can contrastenhanced ultrasonography improve Zone III REBOA placement for prehospital care? J Trauma Acute Care Surg. 2016;80:89-94.

65. Rabinovici R, Bugaev N. Resuscitative Thoracotomy: An Update. Scand J Surg. 2014;103:112-9.

66. Corral E, Silva J, Suarez RM, Nunez J, Cuesta C. A successful emergency thoracotomy performed in the field. Resuscitation. 2007;75:530-3.

67. Van Natta TL, Smith BR, Bricker SD, Putnam BA. Hilar control in penetrating chest trauma: a simplified approach to an underutilized maneuver. J Trauma. 2009:66:1564-9.

68. Wilson A, Wall Jr MJ, Maxson R, Mattox K. The pulmonary hilum twist as a thoracic damage control procedure. Am J Surg. 2003;186:49-52.

69. Wall Jr MJ, Pepe PE, Mattox KL. Successful roadside resuscitative thoracotomy: case report and literature review. J Trauma. 1994;36:131-4.

70. Davies GE, Lockey DJ. Thirteen survivors of prehospital thoracotomy for penetrating trauma: a prehospital physician-performed resuscitation procedure that can yield good results. J Trauma. 2011;70:E75-8.

71. Lockey DJ, Davies G. Pre-hospital thoracotomy: a radical resuscitation intervention come of age? Resuscitation. 2007;75:394-5.
72. Matsumoto H, Mashiko K, Hara Y, Kutsukata N, Sakamoto Y, Takei K, et al. Role of resuscitative emergency field thoracotomy in the Japanese helicopter emergency medical service system. Resuscitation. 2009;80:1270-4.

73. Flaris AN, Simms ER, Prat N, Reynard F, Caillot J-L, Voiglio EJ. Clamshell incision versus left anterolateral thoracotomy. Which one is faster when performing a resuscitative thoracotomy? The tortoise and the hare revisited. World J Surg. 2015;39:1306-11.

74. Coats TJ, Keogh S, Clark H, Neal M. Prehospital resuscitative thoracotomy for cardiac arrest after penetrating trauma: rationale and case series. J Trauma. 2001;50:670-3.

75. Stannard A, Morrison JJ, Scott DJ, Ivatury RA, Ross JD, Rasmussen TE. The epidemiology of noncompressible torso hemorrhage in the wars in Iraq and Afghanistan. J Trauma Acute Care Surg. 2013;74:830-4.

76. Narvestad JK, Meskinfamfard M, Soreide K. Emergency resuscitative thoracotomy performed in European civilian trauma patients with blunt or penetrating injuries: a systematic review. Eur J Trauma Emerg Surg. 2015.

77. Seamon MJ, Haut ER, Van AK, Barbosa RR, Chiu WC, Dente CJ, et al. An evidence-based approach to patient selection for emergency department thoracotomy: A practice management guideline from the Eastern Association for the Surgery of Trauma. J Trauma Acute Care Surg. 2015;79:159-73.

78. Monsieurs KG, Nolan JP, Bossaert LL, Greif R, Maconochie IK, Nikolaou NI, et al. European Resuscitation Council Guidelines for Resuscitation 2015: Section 1. Executive summary. Resuscitation. 2015;95:1-80.

79. Holcomb JB, McMullin NR, Pearse L, Caruso J, Wade CE, Oetjen-Gerdes L, et al. Causes of death in U.S. Special Operations Forces in the global war on terrorism: 2001-2004. Ann Surg. 2007;245:986-91.

80. Rabinovici R. Sixty-Seven Consecutive Resuscitative Thoracotomies by A Single Surgeon. Scand J Surg. 2014;103:156-60.

81. Seamon MJ, Pathak AS, Bradley KM, Fisher CA, Gaughan JA, Kulp H, et al. Emergency department thoracotomy: still useful after abdominal exsanguination? J Trauma. 2008;64:1-7.

82. Duggan M, Rago A, Sharma U, Zugates G, Freyman T, Busold R, et al. Self-expanding polyurethane polymer improves survival in a model of noncompressible massive abdominal hemorrhage. J Trauma Acute Care Surg. 2013;74:1462-7.

83. Rago AP, Marini J, Duggan MJ, Beagle J, Runyan G, Sharma U, et al. Diagnosis and deployment of a self-expanding foam for abdominal exsanguination: Translational questions for human use. J Trauma Acute Care Surg. 2015;78:607-13.

84. Jaskille A, Schechner A, Park K, Williams M, Wang D, Sava J. Abdominal insufflation decreases blood loss and mortality after porcine liver injury. J Trauma. 2005;59:1305-8.

85. Velmahos GC, Spaniolas K, Tabbara M, Duggan M, Li Y, De Moya M, et al. Abdominal insufflation decreases blood loss without worsening the inflammatory response: implications for prehospital control of internal bleeding. Am Surg. 2008;74:297-301.

86. Velmahos GC, Spaniolas K, Duggan M, Alam HB, Tabbara M, De Moya M, et al. Abdominal insufflation for control of bleeding after severe splenic injury. J Trauma. 2007;63:285-8.

87. Kasotakis G, Duggan M, Li Y, O'Dowd D, Baldwin K, De Moya MA, et al. Optimal pressure of abdominal gas insufflation for bleeding control in a severe swine splenic injury model. J Surg Res. 2013;184:931-6.

88. Sava J, Velmahos GC, Karaiskakis M, Kirkman P, Toutouzas K, Sarkisyan G, et al. Abdominal insufflation for prevention of exsanguination. J Trauma. 2003:54:590-4.

89. Peev MP, Rago A, Hwabejire JO, Duggan MJ, Beagle J, Marini J, et al. Self-expanding foam for prehospital treatment of severe intra-abdominal hemorrhage: dose finding study. J Trauma Acute Care Surg. 2014;76:619-23.

90. Rago AP, Larentzakis A, Marini J, Picard A, Duggan MJ, Busold R, et al. Efficacy of a prehospital self-expanding polyurethane foam for noncompressible hemorrhage under extreme operational conditions. J Trauma Acute Care Surg. 2015;78:324-9.

91. Rago AP, Duggan MJ, Beagle J, Peev MP, Marini J, Hwabejire JO, et al. Selfexpanding foam for prehospital treatment of intra-abdominal hemorrhage: 28-day survival and safety. J Trauma Acute Care Surg. 2014;77:S127-33.

92. Rago A, Duggan MJ, Marini J, Beagle J, Velmahos G, De Moya MA, et al. Self-expanding foam improves survival following a lethal, exsanguinating iliac artery injury. J Trauma Acute Care Surg. 2014;77:73-7.

93. Vertrees A, Wakefield M, Pickett C, Greer L, Wilson A, Gillern S, et al. Outcomes of primary repair and primary anastomosis in war-related colon injuries. J Trauma. 2009;66:1286-91. 
94. Mesar T, Martin D, Lawless R, Podbielski J, Cook M, Underwood S, et al. Human dose confirmation for self-expanding intra-abdominal foam: A translational, adaptive, multicenter trial in recently deceased human subjects. J Trauma Acute Care Surg. 2015;79:39-46.

95. White JM, Cannon JW, Stannard A, Markov NP, Spencer JR, Rasmussen TE. Endovascular balloon occlusion of the aorta is superior to resuscitative thoracotomy with aortic clamping in a porcine model of hemorrhagic shock. Surgery. 2011;150:400-9.

96. Avaro JP, Mardelle V, Roch A, Gil C, de Biasi C, Oliver M, et al. Forty-minute endovascular aortic occlusion increases survival in an experimental model of uncontrolled hemorrhagic shock caused by abdominal trauma. J Trauma. 2011;71:720-5

97. Ogura T, Lefor AT, Nakano M, Izawa Y, Morita H. Nonoperative management of hemodynamically unstable abdominal trauma patients with angioembolization and resuscitative endovascular balloon occlusion of the aorta. J Trauma Acute Care Surg. 2015;78:132-5.

98. Norii T, Crandall C, Terasaka Y. Survival of severe blunt trauma patients treated with resuscitative endovascular balloon occlusion of the aorta compared with propensity score-adjusted untreated patients. J Trauma Acute Care Surg. 2015;78:721-8.

99. van Vugt $A$, van Kampen A. An unstable pelvic ring. The killing fracture. J Bone Joint Surg (Br). 2006;88:427-33.

100. Halawi MJ. Pelvic ring injuries: Emergency assessment and management J Clin Orthop Trauma. 2015;6:252-8.

101. Papakostidis C, Giannoudis PV. Pelvic ring injuries with haemodynamic instability: efficacy of pelvic packing, a systematic review. Injury. 2009;40 Suppl 4:S53-61.

102. Eastridge BJ, Starr A, Minei JP, O'Keefe GE, Scalea TM. The importance of fracture pattern in guiding therapeutic decision-making in patients with hemorrhagic shock and pelvic ring disruptions. J Trauma. 2002;53:446-50.

103. Spanjersberg WR, Knops SP, Schep NWL, van Lieshout EMM, Patka P, Schipper IB. Effectiveness and complications of pelvic circumferential compression devices in patients with unstable pelvic fractures: a systematic review of literature. Injury. 2009;40:1031-5.

104. Holstein $\mathrm{JH}$, Culemann U, Pohlemann T. What are predictors of mortality in patients with pelvic fractures? Clin Orthop Relat Res. 2012:470:2090-7.

105. Scott I, Porter K, Laird C, Greaves I, Bloch M. The prehospital management of pelvic fractures: initial consensus statement. Emerg Med J. 2013;30: 1070-2

106. Knops SP, Patka P, Schepers T, Lieshout E. Bekkenbanden voor actue stabilisatie van instabiele bekkenfracturen. Nederlands tijdschrift voor Traumatologie. 2011. p. 126-31.

107. Tan ECTH, van Stigt SFL, van Vugt AB. Effect of a new pelvic stabilizer $(T-P O D(R))$ on reduction of pelvic volume and haemodynamic stability in unstable pelvic fractures. Injury. 2010;41:1239-43.

108. Croce MA, Magnotti LJ, Savage SA, Wood GW, Fabian TC. Emergent pelvic fixation in patients with exsanguinating pelvic fractures. J Am Coll Surg. 2007;204:935-9.

109. Krieg JC, Mohr M, Ellis TJ, Simpson TS, Madey SM, Bottlang M. Emergent stabilization of pelvic ring injuries by controlled circumferential compression: a clinical trial. J Trauma. 2005;59:659-64.

110. Pizanis A, Pohlemann T, Burkhardt M, Aghayev E, Holstein JH. Emergency stabilization of the pelvic ring: Clinical comparison between three different techniques. Injury. 2013;44:1760-4.

111. Knops SP, Schep NWL, Spoor CW, van Riel MPJM, Spanjersberg WR, Kleinrensink GJ, et al. Comparison of three different pelvic circumferential compression devices: a biomechanical cadaver study. J Bone Joint Surg Am. 2011;93:230-40.

112. Lee C, Porter K. The prehospital management of pelvic fractures. Emerg Med J. 2007;24:130-3.

113. Morrison JJ, Percival TJ, Markov NP, Villamaria C, Scott DJ, Saches KA, et al. Aortic balloon occlusion is effective in controlling pelvic hemorrhage. J Surg Res. 2012;177:341-7.

114. White JM, Cannon JW, Stannard A, Spencer JR, Hancock H, Williams K, et al. A porcine model for evaluating the management of noncompressible torso hemorrhage. J Trauma. 2011;71:S131-8.

115. Markov NP, Percival TJ, Morrison JJ, Ross JD, Scott DJ, Spencer JR, et al. Physiologic tolerance of descending thoracic aortic balloon occlusion in a swine model of hemorrhagic shock. Surgery. 2013;153:848-56.

116. London HEMS. First prehospital REBOA. 2014. https://londonsairambulance. co.uk/our-service/news/2014/06/we-perform-worlds-first-pre-hospital-reboa.
117. Biffl WL, Fox CJ, Moore EE. The role of REBOA in the control of exsanguinating torso hemorrhage. J Trauma Acute Care Surg. 2015;78:1054-8.

118. Thorson CM, DuBose JJ, Rhee P, Knuth TE, Dorlac WC, Bailey JA, et al. Military trauma training at civilian centers: a decade of advancements. J Trauma Acute Care Surg. 2012;73:\$483-9.

119. Morrison JJ, Hunt N, Midwinter M, Jansen J. Associated injuries in casualties with traumatic lower extremity amputations caused by improvised explosive devices. Br J Surg. 2012;99:362-6.

120. Mathews ZR, Koyfman A. Blast Injuries. J Emerg Med. 2015;49:573-87.

121. Philippe JM, Brahic O, Carli P, Tourtier JP, Riou B, Vallet B. French Ministry of Health's response to Paris attacks of 13 November 2015. Crit Care. 2016:20:85.

122. King DR, Larentzakis A, Ramly EP. Tourniquet use at the Boston Marathon bombing: Lost in translation. J Trauma Acute Care Surg. 2015;78:594-9.

123. Glassberg E, Nadler R, Erlich T, Klien Y, Kreiss Y, Kluger Y. A Decade of Advances in Military Trauma Care. Scand J Surg. 2014;103:126-31.

124. Drew B, Bennett BL, Littlejohn L. Application of current hemorrhage control techniques for backcountry care: part one, tourniquets and hemorrhage control adjuncts. Wilderness Environ Med. 2015;26:236-45.

125. Hodgetts TJ, Mahoney PF, Russell $M Q$, Byers $M$. $A B C$ to $<C>A B C$ : redefining the military trauma paradigm. Emerg Med J. 2006;23:745-6.

126. Douma M, Brindley PG. Abdominal aortic and iliac artery compression following penetrating trauma: a study of feasibility. Prehosp Disaster Med. 2014;29:299-302.

127. Kheirabadi BS, Arnaud F, McCarron R, Murdock AD, Hodge DL, Ritter B, et al. Development of a standard swine hemorrhage model for efficacy assessment of topical hemostatic agents. J Trauma. 2011;71:S139-46.

128. Kragh JFJ, Murphy C, Steinbaugh J, Dubick MA, Baer DG, Johnson JE, et al. Prehospital emergency inguinal clamp controls hemorrhage in cadaver model. Mil Med. 2013;178:799-805

129. Kragh JFJ, Mann-Salinas EA, Kotwal RS, Gross KR, Gerhardt RT, Kheirabadi B, et al. Laboratory assessment of out-of-hospital interventions to control junctional bleeding from the groin in a manikin model. Am J Emerg Med. 2013:31:1276-8.

130. Kheirabadi BS, Terrazas IB, Miranda N, Estep JS, Corona BT, Kragh JFJ, et al. Long-term effects of Combat Ready Clamp application to control junctional hemorrhage in swine. J Trauma Acute Care Surg. 2014;77:S101-8.

131. St John AE, Wang X, Lim EB, Chien D, Stern SA, White NJ. Effects of rapid wound sealing on survival and blood loss in a swine model of lethal junctional arterial hemorrhage. J Trauma Acute Care Surg. 2015;79:256-62.

132. Park TS, Batchinsky Al, Belenkiy SM, Jordan BS, Baker WL, Necsoiu CN, et al. Resuscitative endovascular balloon occlusion of the aorta (REBOA): Comparison with immediate transfusion following massive hemorrhage in swine. J Trauma Acute Care Surg. 2015;79:930-6.

133. Routt MLC, Falicov A, Woodhouse E, Schildhauer TA. Circumferential pelvic antishock sheeting: a temporary resuscitation aid. J Orthop Trauma. 2006;20:S3-6.

134. Nunn T, Cosker TDA, Bose D, Pallister I. Immediate application of improvised pelvic binder as first step in extended resuscitation from life-threatening hypovolaemic shock in conscious patients with unstable pelvic injuries. Injury. 2007:38:125-8.

135. Simpson T, Krieg JC, Heuer F, Bottlang M. Stabilization of pelvic ring disruptions with a circumferential sheet. J Trauma. 2002;52:158-61.

136. DeAngelis NA, Wixted JJ, Drew J, Eskander MS, Eskander JP, French BG. Use of the trauma pelvic orthotic device (T-POD) for provisional stabilisation of anterior-posterior compression type pelvic fractures: a cadaveric study. Injury. 2008;39:903-6.

137. Prasarn ML, Conrad B, Small J, Horodyski M, Rechtine GR. Comparison of circumferential pelvic sheeting versus the T-POD on unstable pelvic injuries: A cadaveric study of stability. Injury. 2013;44:1756-9.

138. Knops SP, van Lieshout EMM, Spanjersberg WR, Patka P, Schipper IB. Randomised clinical trial comparing pressure characteristics of pelvic circumferential compression devices in healthy volunteers. Injury. 2011;42:1020-6

139. Bottlang M, Simpson T, Sigg J, Krieg JC, Madey SM, Long WB. Noninvasive reduction of open-book pelvic fractures by circumferential compression. J Orthop Trauma. 2002;16:367-73.

140. Bottlang M, Krieg JC, Mohr M, Simpson TS, Madey SM. Emergent management of pelvic ring fractures with use of circumferential compression. J Bone Joint Surg Am. 2002;84-A Suppl 2:43-7.

141. Jowett AJL, Bowyer GW. Pressure characteristics of pelvic binders. Injury. 2007;38:118-21. 